\title{
Desarrollo local en comunidades de artesanos. Patagonia, Iguazú, La Puna, Buenos Aires
}

Ximena González Eliçabe ${ }^{(1)}$

\begin{abstract}
Resumen: El desarrollo local como construcción colectiva es un proceso complejo dinamizado por diversos factores. La artesanía contiene en su génesis los elementos necesarios de este desarrollo. Sin embargo, como parte del sector de la economía creativa, las artesanías deben replantear su subsistencia, estrategias de producción y distribución a partir de la era post-Covid-19. Los procesos colaborativos entre diseñadores y artesanos pueden generar soluciones o innovaciones que impulsen el desarrollo local. Se propone un recorrido a través de la experiencia de la autora en su trabajo de campo, analizando las alternativas y los roles que se plantean en la intervención de diseñadores, artesanos y mercado.
\end{abstract}

Palabras clave: diseño - artesanía - desarrollo - local - producción - ruralidad - identidad - sustentabilidad.

[Resúmenes en inglés y portugués en las páginas 29-30]

(1) Ximena González Eliçabe es Diseñadora Textil (UBA). Artista, investigadora, curadora. Profesora de la Universidad de Palermo en la Facultad de Diseño y Comunicación. Consultora en diseño y artesanía. Trabajó en programas de instituciones públicas como el Ministerio de Turismo de la Nación, el Consejo Federal de Inversiones, entre otras. Realizó exposiciones y obtuvo diversos premios y menciones. Fue directora académica del Centro de Estudios Latinoamericanos La Abadía, Bs. As. Curó las muestras "Ponchos en el Bicentenario" (2017), "Pertenencias Narraciones textiles de mujeres migrantes en el Hemisferio Sur” (2019) en el Museo de Arte Popular José Hernández de Buenos Aires. Este último proyecto fue ganador del Premio "Maleta Abierta" del Programa Iber-Rutas de la Secretaría General Iberoamericana (SEGIB). Es Directora de contenidos de Argentina Xplora.com.

\section{Introducción}

En escenarios de cambios vertiginosos como el actual, debido no sólo a los condicionamientos impuestos por la crisis sanitaria, sino también por la implementación de las tecnologías que se fueron desarrollando en las últimas décadas y que se precipitaron en 
el contexto de aislamiento que atravesamos, afloran nuevos tecno-paradigmas, a partir de los cuales se están replanteando las relaciones humanas, laborales y comerciales, los conceptos de productividad y los hábitos de consumo.

Esta compleja interrelación de fenómenos sociales, culturales y económicos en nuestros días ha sido definida por el sociólogo Manuel Castells ${ }^{1}$ como un nuevo modo de desarrollo informacional, la "Sociedad red", cuya productividad se basa en la tecnología de generación de conocimiento, el procesamiento de la información y la comunicación de símbolos. Si bien todos los modos de desarrollo implican cierto grado de conocimiento y procesamiento de información, éste plantea como motor a la acción del conocimiento sobre sí mismo como fuente de productividad.

Ahora, si bien la artesanía es considerada una actividad característica de desarrollo en modelos previos a la revolución industrial, y si ha prevalecido a través del tiempo es por la conexión que tiene con la transmisión de conocimiento como actividad práctica-espiritual. Sus producciones son portadoras de identidades, valores y significados.

Según la UNESCO, las técnicas artesanales tradicionales, al igual que las tradiciones y expresiones orales, los usos sociales, rituales y actos festivos, los conocimientos y usos relacionados con la naturaleza y el universo, son manifestaciones del patrimonio cultural inmaterial, del que la artesanía forma parte.

Esto nos invita a reflexionar acerca de la importancia de poner a la cultura como núcleo del desarrollo.

El desarrollo local es una construcción colectiva ligada a diferentes factores que implican una integración entre lo económico, lo social, lo cultural, lo ambiental, etc. a nivel local, utilizando los recursos del territorio para impulsar el bienestar de sus miembros a través de la relación con otras comunidades y agentes.

Es un proceso complejo que apunta a reforzar el espíritu colectivo mediante estrategias que aprovechan la potencialidad de determinada región o grupo, en pos de resultados con impacto positivo en la población, dando cuenta de un proceso transparente y participativo. La artesanía contiene en su génesis los elementos necesarios para movilizar este desarrollo.

En las últimas décadas se pusieron en marcha programas para alcanzar estos objetivos en diversas regiones. Algunos de los oficios fueron valorizados y con el aporte del diseño comenzaron a integrarse en las cadenas productivas. Varias técnicas fueron redescubiertas o documentadas. Materiales nuevos comenzaron a aparecer a la vez que escasearon otros. Sin embargo, como parte del sector de la economía creativa, las artesanías deben replantear su subsistencia, estrategias de producción y distribución a partir de la era post-Covid-19. Lo que caracteriza a las producciones de significado del siglo XXI, es que hay una inquietud creciente por la producción colaborativa, es un arte menos propenso a realizar obras materiales que a diseñar experiencias.

Este trabajo reflexiona acerca de cómo a partir de procesos colaborativos entre diseñadores y artesanos se pueden generar aportes innovadores impulsando a la vez el desarrollo local. Propone un recorrido a través de la experiencia de la autora, quien habiendo realizado trabajo de campo en distintas comunidades de artesanos de Argentina por más de 20 años, analiza los roles de las distintas partes participantes y señala que la intervención del diseñador debe ser absolutamente respetuosa y responsable. 


\section{Transferencia de saberes ida y vuelta}

El desarrollo artesanal es dinámico, acompaña procesos cambiantes de la cultura misma, pero a la vez la introducción de cambios drásticos o políticas equivocadas pueden derivar en pérdida de la identidad local, utilización de la mano de obra artesanal como un componente de poco valor, despersonalizado y escindido de su contexto; repetición de fórmulas o productos que saturan el mercado y por consiguiente disminuyen su demanda; falta de reconocimiento social y económico de los oficios, frustración, abandono de la actividad por parte de los artesanos o sus descendientes. Sin mencionar los intentos por incorporar otras propuestas como las manualidades a los espacios artesanales tradicionales sin criterio, como si fuera lo mismo, lo que a pesar de tener intenciones de inclusión, por falta de empleo local, de sumar actores de la economía informal (a veces referida como economía social) no proporcionan valor agregado, no son generadores de tecnología, ni aportan a la cadena de valor, en síntesis no generan conocimiento ni riqueza.

En los últimos años el país atravesó diversas crisis que derivaron en la desaparición del empleo tradicional, formal y en un deterioro del tejido social. Se recurrió a veces a políticas públicas que en lugar de promover las actividades locales las ignoraron, desalentaron o tomaron rumbos equivocados, así como también se superpusieron desde diversas áreas ejecutivas. Los cambios de gestión generaron discontinuidad de los programas, que muchas veces no funcionaron sin subvención desde el Estado, fueron pocos los intentos por propiciar el establecimiento de grupos autosuficientes, o resultaron de corta duración y sin el acompañamiento adecuado.

Por lo general las políticas (públicas y privadas) que se aplican al sector tienen que ver con dos vertientes, 1 - la económica, basada en la manufactura para satisfacer ciertas demandas. 2- la social, asistida por programas de ayuda a poblaciones vulnerables o minorías entre las que siempre se incluyen las mujeres, los pueblos indígenas y algunas minorías relacionadas con lo rural. Desde hace tiempo estos grupos se mueven en una línea de frágil equilibrio, entre la sustentabilidad tanto de sus ecosistemas como de la economía de sus comunidades o familias. Sin embargo, si bien son vulnerables tienen como fortaleza su capacidad de persistir, a través de un conocimiento compartido. Siempre han resistido, desde su sistema de creencias y pertenencia logran sostenerse como comunidad.

Los procesos artesanales manejan el uso de recursos de una manera diferente, con materiales nobles y un acercamiento respetuoso que preserva el medio ambiente, sin depredar. Esto, no sólo representa un importante ejemplo a seguir para cualquier diseñador, sino que también se trata de procesos que deben y tienen que ser preservados; como diseñadores debemos escuchar a los hacedores y aprender de esos procesos respetuosos del cuidado del entorno, que aprovechan los ciclos naturales y no generan desperdicio ni polución. Esos mismos criterios pueden transpolarse a otras áreas de la producción, pensando en productos puros, limpios, de baja escala pero de compleja elaboración y eficaz distribución. Sin dudas el desafío más importante en esta época post-pandemia es incorporar las tecnologías de la información, mejorar la conectividad, para comunicarse, encontrar los canales adecuados de distribución, establecer reglas claras y medios asequibles para que el flujo de productos llegue a los destinatarios que aprecien sus cualidades, donde quieran que estén. No sólo por la posibilidad del encuentro con el turista, sino también guiados por 
algoritmos capaces de detectar la demanda o un potencial interés. El rol de la logística no es menor, así como las nuevas plataformas de pago y el dinero virtual. Los nodos de cadenas de bloques - blockchain- podrían contribuir a un futuro desarrollo certificando el origen, la autenticidad y la calidad de las piezas como un nft (Non Fungible Token), evitar intermediación en productos terminados e insumos. Este aporte de conocimiento puede impulsar el desarrollo de sistemas que resuelvan necesidades de usuarios con intercambio peer to peer-de igual a igual-, o que impulsen la co-creación.

Por ende es necesario que las estrategias de desarrollo apunten al largo plazo, incluyendo mejoras en los campos en donde éstas son necesarias (en lo tecnológico, comunicacional, logístico, y servicios asociados), que ayuden a expandir la actividad, generando oportunidades de integración a los mercados, diferenciándose por la calidad, autenticidad y confiabilidad que el producto hecho a mano con material noble encierra.

La manera en la que pensamos estas estrategias debe poner el foco en el intercambio transdisciplinario de saberes, promoviendo la cultura e identidad, respetando la diversidad cultural, los oficios tradicionales y la producción responsable, así como el cuidado de los recursos naturales. Integrando estos preceptos al desarrollo tecnológico se puede impulsar la economía regional, potenciando las cadenas de valor, a los actores del territorio generando liderazgos, empleo local y arraigando a los jóvenes en su lugar de origen.

A veces el criterio parte de la proyección con respecto a la tradición y la modernidad y se habla de la artesanía tradicional y de neo-artesanía; que por lo general se identifica con una artesanía urbana que trabaja a partir de criterios estéticos asimilados del arte y del diseño (Benitez Aranda, 2009, p. 9).

Ayudando a sistematizar y aportando innovación, el diseño puede ser un puente entre lo tradicional y lo contemporáneo. Entre los pequeños productores, guardianes de los oficios y los usuarios, insertos en un mercado cada vez más exigente basado en la diferenciación y la personalización. Por eso la metodología del diseño también debe estar en sintonía con lo tradicional, respetando los tiempos de los procesos, dándole protagonismo a sus creadores, potenciando lo propio de una región. La intervención no debe afectar a la identidad local sino proyectarla, sin modificar su esencia, contribuyendo a una mejor comunicación y comercialización de las artesanías, jerarquizándolas y dándoles lugar tanto en el espacio del arte -como arte popular-, como así también en productos de la vida cotidiana -a través del diseño-.

A su vez, es importante destacar que una gran concentración de la oferta en este campo, está orientada al sector turístico, donde lo vivencial tiene tanto valor como el producto mismo. Por eso al referirnos en los párrafos anteriores a que actualmente se tiende a un arte menos propenso a producir obras materiales que a diseñar experiencias, estamos hablando no sólo de la experiencia del usuario al consumir o utilizar el producto (en este caso un bien cultural) sino también al tomar contacto con quienes lo elaboraron, conociendo sus procesos y contextos para tener una mejor comprensión del mismo. El rol del souvenir-recuerdo artesanal- es el de expandir la experiencia del visitante espacial y temporalmente. Pero hay otras piezas más elaboradas, que pueden llegar hasta el espacio más íntimo en la cotidianeidad del usuario, estribando en su función y contando la historia 
que hay detrás. ¿Podrá recrearse esa experiencia a través de la virtualidad o los sistemas de comunicación a distancia? Si bien el contacto directo con el contexto y con sus actores es irreemplazable, podemos proponer nuevas formas de acercamiento a estas realidades, generando contenidos, contando historias y dando visibilidad a sus protagonistas. También hay que considerar la diversidad de conocimientos que pueden aportar las comunidades de artesanos -indígenas, criollos, urbanos- dándoles el lugar que merecen.

Un ejemplo de ello son las capacitaciones a distancia, como el curso de tejido de mallas en chaguar (fibra vegetal de bromelias) que la destacada artesana wichí María del Carmen Toribio brindó a través de la plataforma de la Asociación Amigos del MAP (Museo de Arte Popular José Hernández) desde la localidad de Ingeniero Juárez, en el corazón del monte, en el oeste de la provincia de Formosa, noreste de Argentina.

Reforzar las redes de artesanos también tiene efectos poderosos en la comunidad, no sólo en el individuo. Es necesario trabajar también con socios técnicos estratégicos, como empresas sociales en diferentes países, diseñadores y especialistas en logística, para proporcionar financiamiento inicial y aportes de diseño.

El impulso por el desarrollo que emana del diseño y de la aplicación de sus metodologías para resolver necesidades, potencian la creación, las prácticas y preservación del pensamiento del "hacer" presente en el patrimonio artesanal. Poner atención a los procedimientos es esencial, ya que devienen en una clave de lectura para interpretar la cristalización material del pensamiento procedimental.

\section{Casos emblemáticos de desarrollo de diseño con comunidades de artesanos}

Un caso de éxito en este sentido es "Elementos Argentinos" ${ }^{2}$ una empresa de diseño dedicada a la producción de alfombras de lana hechas a mano, que trabaja con comunidades de tejedores en distintos puntos del país. Fundada en 2005 por Pablo Mendevil y Fernando Bach, es una empresa B certificada (de triple impacto: económico, social y ambiental), que sigue los lineamientos del comercio justo, generando productos de fuerte identidad local, alta calidad y diseño, dando trabajo a más de 140 familias de artesanos durante todo el año, logrando quebrar la marcada estacionalidad que este tipo de productos suele tener (debido a las oscilaciones del turismo, entre otros factores). Con una organización empresarial eficiente, comenzaron a comercializar estos tejidos de los cerros (de Tucumán, Salta y Jujuy en el noroeste argentino) y del monte (Santiago del Estero) en la ciudad de Buenos Aires y sus alrededores, para expandirse en la actualidad con dos locales en Buenos Aires y presencia en importantes centros de diseño en otros países - exportan un $20 \%$ de su producción-con una propuesta innovadora y consciente, prestando atención a toda la cadena de valor y al medio ambiente, obteniendo resultados económicos positivos. Sus productos se destacan por el uso de las técnicas tradicionales, materiales nobles, a los que también se añade un proceso de creación conjunto con las comunidades de artesanos. Proponen acciones que propician la experimentación para la generación de nuevos diseños, asumiendo la empresa los riesgos que esto conlleva para los artesanos, con resultados muy positivos. Pablo Mendevil, se refiere en una entrevista realizada recientemente por la auto- 
ra, a que una de sus máximas es "no perderse en la traducción" escuchar y comprender la manera en que se produce, entender el entorno del otro, su contexto, tiempos y posibilidades de producción, que finalmente van a formar parte del resultado final y del contexto que el producto tendrá, tratando de mantenerlo visible en su exhibición y comunicación. Otra empresa de diseño que trabaja colaborativamente con comunidades de tejedores es "Manto" ${ }^{3}$ creada por Clara de la Torre, a la que luego se sumó Diana Dai Chee Chaug, un proyecto textil diseñado en el año 1996 para poder compartir, conocer y vivenciar la cultura de las comunidades originarias de las provincias de Salta y Jujuy. Desde ese tiempo trabajan juntos con el fin de mantener viva su sabiduría y oficios, priorizando sus relaciones, el respeto por los tiempos y la naturaleza, sus costumbres y necesidades. En la búsqueda de sostener los procesos productivos tradicionales apoyaron a la comunidad de San Isidro en Salta, en un Proyecto comunitario desde el primer eslabón del tejido que es el hilado manual, muchas veces invisibilizado y poco valorado. Alentaron a la comunidad a la producción del hilado en molinos mediante la fuerza hidráulica del río que les permite el aprovechamiento de un recurso natural, para producir de manera más rápida y eficiente, reforzando el vínculo con la naturaleza, con el río como eje vital de esta comunidad, que viene en un lugar árido, entre cerros a 3000 m.s.n.m. y que aprovecha la fuerza de la naturaleza y sus ciclos. Porque esta actividad sólo puede realizarse en la época en que se inician los deshielos, cuando el torrente tiene una intensidad moderada. Manto pone énfasis no sólo en el resultado final que se aprecia con gran factura en los productos, sino también en los procesos y en la relación con sus hacedores. Su volumen de producción es bajo porque la intención no es la de la fabricación de productos, sino la de pensar qué se puede hacer con esa producción que amalgama el tejido social y cultural de esa población en relación directa con la naturaleza. La empresa ayuda a sostener a esa comunidad comprando toda su producción anual, dándole destino a las piezas en sus colecciones de indumentaria, pensadas e intervenidas con una mirada contemporánea, prendas de calidad que se venden en Palermo Chico, la zona más chic de Buenos Aires.

Pero no sólo hay experiencias de colaboración desde las empresas de diseño, sino que se ha trabajado desde las mismas comunidades en proyectos de revalorización de sus tradiciones artesanales, como algunos de los casos de los que tuve el privilegio de formar parte, trabajando con instituciones nacionales y provinciales de Argentina. Uno de ellos fue el "Programa de asesoramiento técnico del Corredor de la Puna en la Provincia de Salta, para la protección de las manifestaciones artesanales", del que estuve a cargo entre 2011 y 2013. El Proyecto que involucraba a los gobiernos nacional, provincial y municipales, abarcó geográficamente el corredor turístico de cuatro localidades, articuladas por el trazado ferroviario del "Tren a las Nubes", uno de los principales atractivos turísticos del país, que une la ciudad de Salta con la inmensidad de la Puna en la zona de la pre-cordillera de los Andes. El "Tren a las Nubes" es uno de los tres ferrocarriles más altos del mundo, con un recorrido entre vertiginosas montañas. El trayecto que comienza en la Ciudad de Salta y termina en el Viaducto La Polvorilla, gran obra de ingeniería en el altiplano, y última estación luego de San Antonio de los Cobres, pueblo minero que reconoce antiguos orígenes indígenas, llamado así por encontrarse dentro de su jurisdicción la famosa "Sierra del Cobre" rica en este mineral. Pero mi recorrido terminaba más arriba, al pie del volcán Llullaillaco (6739 m.s.n.m.), al límite con Chile en la Cordillera de los Andes, sitio sagrado de 
las comunidades incas y sus descendientes ${ }^{4}$. Las cuatro poblaciones donde se desarrolló el Proyecto fueron 1) Campo Quijano, zona rural cercana a la ciudad de Salta, con población criolla y con gran parte de la población dedicada al trabajo artesanal, productos regionales y gastronomía típica. 2) Santa Rosa de Tastil (2700 m.s.n.m.), pequeña población con gran patrimonio arqueológico -periodo tardío - 100 DC 1450 DC- entre los que se cuentan las ruinas de una ciudad pre-inca, una zona con gran cantidad de petroglifos y hasta una parte del Qhapaq ñam ${ }^{5}$-camino del inca-. 3) San Antonio de los Cobres, una población con un alto porcentaje de habitantes dedicados la artesanía y cabecera del recorrido del tren. 4) Tolar Grande, a $200 \mathrm{~km}$ de San Antonio de los Cobres por camino de cornisa, 3800 m.s.n.m., esta pequeña población de origen minero cuenta con apenas 200 habitantes, sin luz eléctrica y con una estación de ferrocarril fuera de servicio, abandonada.

En un proceso de ida y vuelta con los artesanos, durante el lapso que duró el proyecto, trabajamos en mejorar los procesos de terminación o acabado de las piezas, interpretar las necesidades del usuario, replantear la morfología de las prendas, generar nuevas tipologías, sin modificar ni los materiales - producto de la obtención de fibras de camélidos y lana que se da en la zona- ni las técnicas tradicionales, ni los motivos ancestrales en la iconografía. También se propuso un trabajo de recuperación iconográfica -con el Museo de Antropología de Salta- para evitar que sólo utilicen algunos motivos repetidos y olviden la riqueza de su patrimonio. Optimizamos los procesos de diseño, producción y exhibición de los productos artesanales. En los textiles se puso el foco en la calidad de hilado (descerdado de las fibras de camélidos) clasificación y tintes naturales, así como en las distintas estructuras del tejido. En las prendas de vestir modificamos accesos, largos modulares, sistemas constructivos, avíos, etc. En la cerámica promovimos los engobes y terminaciones naturales en detrimento de aplicaciones de pigmentos industriales. Trabajamos con líderes de comunidades aledañas más alejadas y menos conectadas, con el objetivo de generar una base de datos actualizada del sector artesanal y de detectar aquellos maestros que aún conservan las técnicas tradicionales. Visitamos a los productores locales de fibras, en especial aquellos dedicados a la vicuña, para incorporar los mejores materiales en las líneas de productos.

Finalmente resolvimos trabajar en dos líneas de productos textiles, una orientada a la moda y al público del tren (turistas) y otra orientada hacia la calidad, con productos atemporales destinados al hogar, la decoración y el equipamiento hotelero. Los resultados del programa fueron mostrados no sólo en los mercados locales, sobre los que se trabajó con un criterio de red, sino también en una exposición en la ciudad capital de la provincia, donde se exhibieron en una sala como cualquier otra pieza patrimonial, montadas e iluminadas con un guión curatorial, un video documental y fotos del contexto. Allí los artesanos fueron los verdaderos protagonistas. Paralelamente se exhibieron productos para la venta, clasificados y ordenados en una sala contigua y se realizaron rondas de negocios con comerciantes y empresas. La exposición se llamó "Hilos, kenkos y caminos. Textiles de la Quebrada del Toro y La Puna" (2013)6. 


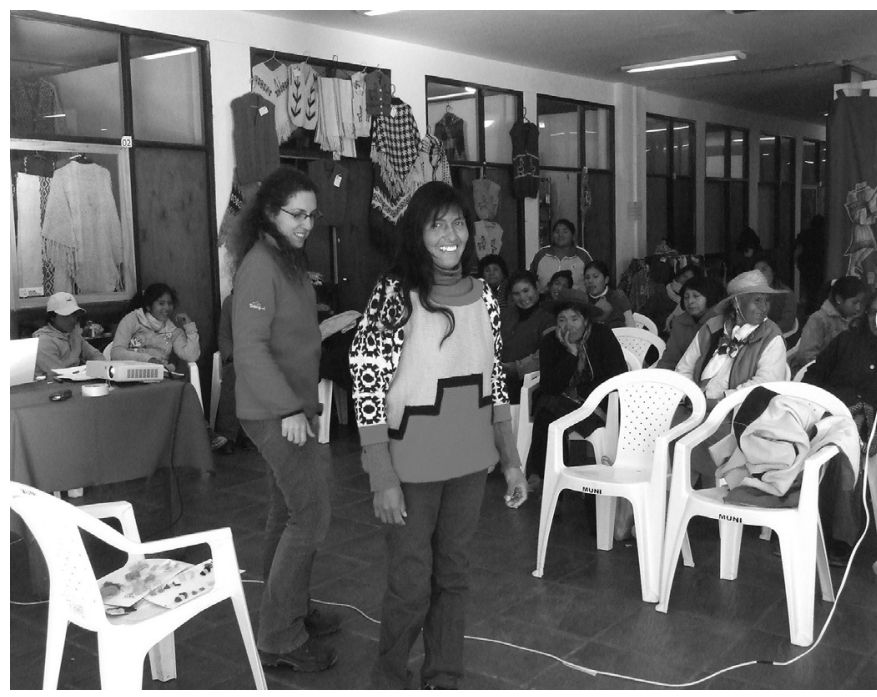

Imagen 2.

Asesoramiento

técnico en el corredor de la Puna. Trabajo de taller en creación de nuevas tipologías, estandarización de medidas y proporciones. Mercado Artesanal de San Antonio de los Cobres, Salta (2013).

Otras experiencias de esta índole sucedieron durante mi intervención en la Patagonia, en el Plan de Desarrollo Turístico de la Meseta central del Chubut y el Programa de destinos turísticos emergentes en la localidad rural de Las Ovejas, limítrofe con Chile en las altas cumbres de la "Cordillera del viento", en la provincia del Neuquén. En esta gran extensión de territorio, pequeños núcleos de criadores de ovejas productoras de lana son a la vez quienes transforman esa materia prima y elaboran productos con una tradición que hunde sus raíces en las culturas mapuches y tehuelches. Allí se puso el foco en las cadenas de valor, la creación de bancos de lana y la comercialización en los destinos emblemáticos de la región andina patagónica como la ruta de los siete lagos, San Martín de los Andes, Villa la Angostura, San Carlos de Bariloche, El Bolsón y Esquel. La exhibición de productos seleccionados se ubicaron en los stands de los aeropuertos y la instalación de vitrinas en hoteles boutiques. A su vez se intentó fortalecer la transmisión del conocimiento de los oficios artesanales de los maestros artesanos a los miembros más jóvenes de sus comunidades. Así como fomentar que los establecimientos turísticos incorporen sus productos en la ambientación o elementos utilitarios como blanquería y menaje, incrementando un estilo local (elegante y austero) con identidad regional, que haga más auténtica e integrada al contexto la experiencia del usuario. 


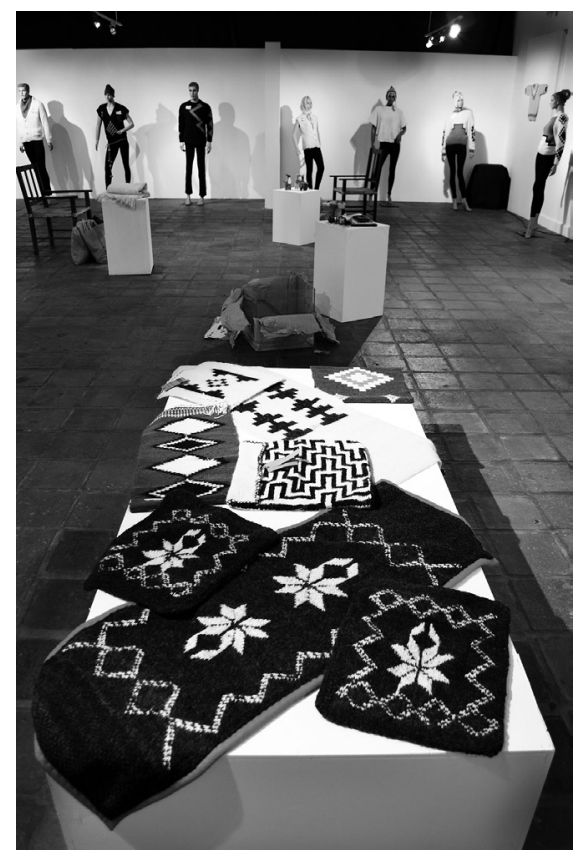

\author{
Imagen 2. Vista \\ de la Exposición \\ "Hilos, kenkos y \\ caminos. Textiles de \\ la Quebrada del Toro \\ y la Puna", curada \\ por la autora. Salta, \\ noviembre 2013.
}

Posiblemente uno de los trabajos de campo con experiencias mas resonantes fue el Acompañamiento técnico a las comunidades Mbyá Guaraní de Iguazú, Provincia de Misiones, en distintas etapas y proyectos impulsados por diversos organismos como el Programa interministerial a nivel nacional " "Turismo Rural con inclusión comunitaria" o con apoyos del Fondo Nacional de las Artes (entre 2013 y 2018). Las aldeas Yriapú y Jasy Porá se encuentran dentro de las 600 hectáreas protegidas destinadas por ley a las comunidades indígenas linderas al Parque Nacional Iguazú donde se encuentran las Cataratas del río homónimo, otro de los principales atractivos turísticos de Sudamérica. Estas comunidades, étnicamente puras y hablantes de su lengua originaria el guaraní, continúan con el estilo de vida tradicional comunitaria, desde su organización política, social y religiosa hasta la producción de objetos de manera tradicional utilizando los materiales que la abundancia de la selva les provee. No obstante, al encontrarse en una zona de gran afluencia turística habían adoptado hábitos de venta en función de la demanda de productos vinculados a ese sector, siendo su mayor punto de venta el Centro de visitantes del Parque Nacional. En la cultura Mbya Guaraní, la artesanía es una actividad colectiva que funciona como construcción social de la comunidad, preservando una doble naturaleza, material y espiritual; esta guarda una estrecha relación con el mundo sobrenatural asociado íntimamente a su vida en la selva. No obstante la realización de piezas artesanales es el principal sustento de estas comunidades. La organización comunitaria para el turismo, proporciona a las 


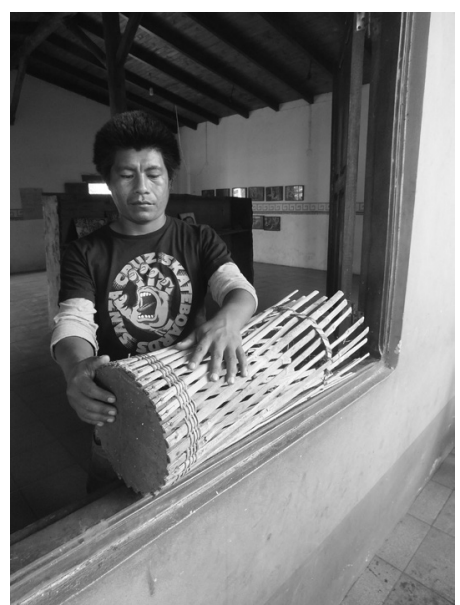

3

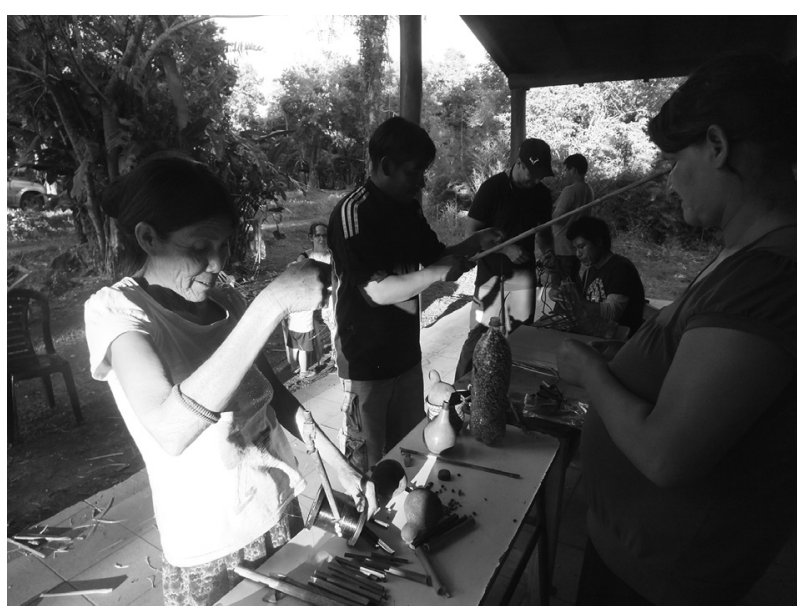

4

Imagen 3. Artesano de la comunidad Yryapú realizando productos para equipamiento hotelero con técnicas y materiales tradicionales. Asesoramiento técnico en Iguazú, provincia de Misiones (2018). Imagen 4. Artesanos de la comunidad Yryapú trabajando en talleres para la innovación de productos artesanales con identidad local. Iguazú, provincia de Misiones (2018).

comunidades una fuente de ingresos genuinos sin abandonar su territorio ni su modo de vida tradicional. Los roles dentro de la comunidad son diferentes para los distintos grupos. Los hombres buscan los materiales vegetales para sus trabajos, construyen las casas, y consiguen el alimento a través de la pesca, la caza o la recolección, que complementan con las compras que realizan en Puerto Iguazú con los ingresos por las ventas de artesanías. Las mujeres se ocupan de los niños, de las semillas, de los animales domésticos, trabajan la cestería con corteza de güembé y caña tacuara. Los hombres realizan tallas en maderas de distinta dureza obtenidas del monte nativo donde está inserta la comunidad, como el cedro misionero, alecrín, guayuvira; cerne de loro negro; guatambú, cancharana; aguay, mora blanca; fumo bravo. Los niños tienen también participación en la vida comunitaria, sus cantos, sus juegos acompañan la tarea diaria de los adultos.

En este programa se contempló la adquisición de equipamiento, como algunas herramientas eléctricas que facilitaron parte del trabajo, como un torno Dremel con distintas puntas, un pirograbador, y herramientas manuales como gubias, sierras, etc. Trabajamos con la comunidad, dentro de sus tiempos y expectativas, en el desarrollo de nuevas tipologías enfocadas a los estilos de vida contemporáneos y no solamente como un souvenir del viaje a Cataratas. Realizamos piezas que combinaron madera, cestería, recubiertos con ornamentaciones en cortezas vegetales, para el equipamiento hotelero y gastronómico como 
lámparas, bandejas, recipientes, marcos, cortinas separadores, etc. que luego comenzaron a comercializar a pedido de emprendedores locales y de los hoteles de lujo que se ubican en la zona.

En ocasiones como las mencionadas, siempre funciona ponerse en el lugar del otro, la noción de alteridad ayuda a comprender y enriquecer la mirada. Tanto para interpretar para quién diseñamos como para encontrar un destello de belleza en la acción mas simple.

\section{Conclusión}

En estas reflexiones nos interpelamos acerca de las formas actuales de configurar y pensar comunidades desde el arte y la artesanía. En este acercamiento de conocimientos compartidos podemos aprender de ida y vuelta con los hacedores, con las historias que hay detrás de ellos. Es posible conocer y comprender a nuestros países o regiones y a sus comunidades artesanales a través del encuentro entre el patrimonio y la generación de conocimiento con propuestas tecnológicas.

Una Comunidad ${ }^{8}$, de acuerdo a la definición de Max Weber, es una relación social que se inspira en el sentimiento subjetivo -afectivo o tradicional- de los partícipes de constituir un todo. Dos de los valores que este autor rescata en una comunidad son la colaboración y el respeto por una tradición común.

Es hora de potenciar las prácticas artesanales individuales y de las comunidades para contribuir de este modo al fortalecimiento social y comunitario, que establezca las bases para el desarrollo local.

Las artesanías tienen un proceso creativo diferente, y se transmite de una manera natural y procesual, en la que se gana experiencia con el hacer. Comprender sus procedimientos permite proponer un nuevo abordaje metodológico, acceder al conocimiento que contienen y elaborar nuevos significados. Los enfoques innovadores aplican un conocimiento transversal, con énfasis en los proyectos experimentales, transdisciplinarios y colaborativos.

Muchos de los procesos artesanales han tenido que replantear las formas de hacer y los materiales debido a la intervención de la industria, del consumo, del avance de la frontera agropecuaria a gran escala, la minería. Esto tiene como resultado la dificultad para acceder a los espacios donde obtenían los materiales para la realización de sus piezas, o la falta de un espacio adecuado para ofrecer sus productos. Si se hicieran más visibles habría una gran cantidad de personas en otros lugares dispuestas a adquirirlos y a pagar por su valor, que incluye los procesos limpios y transparentes que tienen detrás.

A escala global se puede advertir una escasez de recursos, así como de capitales. Tal vez debamos convertirnos en algo más pequeño, más local, bajar la escala de la producción gigantesca de bienes que se fabrican a $20.000 \mathrm{~km}$ de distancia en empresas enormes, bienes que muchas veces ni siquiera necesitamos.

El autor y crítico estadounidense James Howard Kunstler, afirma en una entrevista reciente de Keiser report en RT (Russian TV) que para salir adelante en esta crisis económico-financiera global, se debe volver a la economía real, que "debería emplear a la gente del lugar, tener personas que ocupen nichos económicos y sociales dentro de la comunidad, 
de modo que desempeñen diferentes papeles y así tener una sociedad consistente en lugar de tener una sociedad de consumidores "pacman"” (Kunstler, 2021).

Para reinventarse luego de este colapso producido no sólo por la crisis sanitaria sino también por el deterioro de los modelos financieros y productivos, quizás haya que pensar en reconstruir la economía a través de las economías locales, aunque esto implique un menor impacto en el consumo global, consumir bienes más duraderos, con materiales de calidad, con menor impacto ambiental, pero cargados de significado. Para eso es preciso reorganizar nuestro día a día y nuestras actividades cotidianas, construir comunidades reales que operen en el mundo virtual.

En la artesanía la creación puede ser individual o colectiva, su actividad promueve formas de asociación social basadas en el sentido de pertenencia, a la familia y la comunidad. Ha evolucionado a través de muchos años, siglos, ha podido atravesar la modernidad que ha creído prescindir de ella; ha entrado en la contemporaneidad como una alternativa a muchas de las cosas que podrían dificultar desarrollos futuros. La artesanía es sólida, tiene contenido, valores, combate la deshumanización y celebra el encuentro con lo más auténtico. Ayuda a recordar, pensar y construir en la práctica cotidiana.

\section{Notas}

1. Manuel Castells: Profesor de la Universitat Oberta de Catalunya, ocupa la cátedra Wallis Annenberg de Tecnología de la Comunicación y Sociedad; Universidad de California del Sur. Catedrático emérito de Sociología y Planificación Urbana y Regional; Universidad de California/Berkeley y profesor visitante de Ciencia, Tecnología y Sociedad del MIT.

2. Elementos Argentinos: https://elementosargentinos.com.ar/

3. Manto: https://mantoabrigos.com/

4. En un descubrimiento arqueológico realizado por la National Geographic Society y la Universidad Católica de Salta se encontró una "capacocha" o santuario de altura, con los cuerpos momificados naturalmente de tres niños ofrendados a la montaña, encontrados por los arqueólogos Johan Reinhard y Constanza Ceruti en 1999.

5. Qhapaq Nan, en lengua quechua significa "camino principal", en referencia a la red pre hispánica de caminos y estructuras relacionadas de comunicación, intercambio y defensa que se extiende por más de 30.000 kilómetros y que alcanzó su máxima expansión en el siglo XV cuando fue consolidado por los Incas.

6. Este Proyecto fue financiado por el Ministerio de Turismo de la Nación, dentro del Programa de Destinos Emergentes (PROFODE) y el Ministerio de Turismo y Cultura de la Provincia de Salta y además apoyado comprometidamente por muchos técnicos y referentes locales que trabajaron el él.

7. Programa "Turismo Rural con inclusión comunitaria", realizado por la Dirección de Desarrollo de la Oferta perteneciente a la Dirección Nacional de Desarrollo Turístico del Ministerio de Turismo de la Nación, con el Ministerio de Agricultura, el Ministerio de Desarrollo Social y el ministerio de Trabajo de Argentina, formó parte del Plan Federal Estratégico de Turismo Sustentable. 
8. Para Ferdinand Tönnies (1887; Comunidad y sociedad), antecesor de las teorías de Weber, Gemeinschaft (traducido frecuentemente como comunidad) es un tipo ideal de organización social donde sus miembros se regulan por reglas tradicionales o creencias comunes sobre su comportamiento y responsabilidad para con la comunidad. Las personas tienen relaciones cara a cara, sencillas y directas entre sí que están determinadas por Wesenwille (voluntad natural), es decir, emociones y expresiones de sentimiento que surgen de forma natural y espontánea.

\title{
Bibliografía
}

Álvaro, D. (2010). Los conceptos de "comunidad" y "sociedad" de Ferdinand Tönnies. Papeles del CEIC \# 52, marzo 2010. Recuperado en http://www.identidadcolectiva.es/pdf/52.pdf

Benítez Aranda, S. (2006). La artesanía como factor de Desarrollo económico, social y cultural; a la luz de los nuevos conceptos de cultura y desarrollo. Revista Cultura y Desarrollo No7. UNESCO. La Habana.

Castro H., P. de J. (2016). "Evolución de la Sociología. Futuro e historia”. Revista de Museología KÓOT, AÑO 6, n.o 7. Recuperado en https://www.lamjol.info > KOOT > article > view

Kunstler, J. H. (2021). "Estamos entrando en un periodo de la historia de no crecimiento". Recuperado en https://www.youtube.com/watch?v=pWWP88DeEkY

Weber, M. (2004). “Economía y Sociedad. Esbozo de la sociología comprensiva”. México: Fondo de cultura económica.

\begin{abstract}
Local development as a collective construction is a complex process fueled by various factors.

Craftsmanship contains in its genesis the necessary elements for this development. However, as part of the creative economy sector, handicrafts must rethink their subsistence, production and distribution strategies beginning in the post-Covid-19 era. Collaborative processes between designers and artisans can generate solutions or innovations that drive local development. A journey through the author's experience in her field work is proposed, analyzing the alternatives and the roles that arise in the intervention of designers, artisans and the market.
\end{abstract}

Keywords: design - crafts - local development - production - rurality - identity - popular - sustainability.

Resumo: O desenvolvimento local como uma construção coletiva é um processo complexo alimentado por vários fatores. $\mathrm{O}$ artesanato contém em sua gênese os elementos necessários para esse desenvolvimento. No entanto, como parte do setor da economia criativa, o artesanato deve repensar suas estratégias de subsistência, produção e distribuição a partir 
da era pós-Covid-19. Processos colaborativos entre designers e artesãos podem gerar soluções ou inovações que impulsionem o desenvolvimento local. É proposta uma viagem pela experiência da autora no seu trabalho de campo, analisando as alternativas e os papéis que surgem na intervenção de designers, de artesãos e no mercado.

Palavras chave: design - artesanato - desenvolvimento - local - produção - ruralidad identidade - sustentabilidade.

[Las traducciones de los abstracts fueron supervisadas por el autor de cada artículo] 